\title{
CONTRIBUTI PER PETAR POZDANČIĆ E LA SUA BOTTEGA A TRAÙ
}

\author{
Ivo Babić
}

\author{
I. Babić \\ Trogir \\ ibabic@gradst.hr
}

\begin{abstract}
A Petar Pozdančić scultore e architetto, molto attivo ai primi del XV secolo a Zara, Bribir, Traù e Venezia, è attribuita con certezza una sola opera: $i$ doccioni sulla cattedrale traurina per $i$ quali fu pagato nell'anno 1416. Essi costituiscono indizi per l'attribuzione allo stesso maestro di alcune opere di scultura ornamentale a Traù.
\end{abstract}

Key words: Petar Pozdančić, Traù, gothic sculptures

In questo contributo attribuisco a Petar Pozdančić Radmilov e alla sua bottega alcuni lavori a Traù: quattro teste immurate nel cortile del Palazzo del Comune; una trifora sul Piccolo Palazzo Cippico. A questo maestro attribuisco anche lo stemma e la testa - frammento di una finestra gotica nel Palazzo Lucić. Avanzo anche l'ipotesi che il maestro lapicida Pozdančić abbia contribuito alla decorazione della parte finale del primo piano del campanile della cattedrale di Traù, ciò che potrebbe essere argomento di uno studio a se stante e più esauriente, per il quale si richiederebbe una documentazione fotografica dettagliata.

Fondamento di queste attribuzioni sono i doccioni (gargouilles) con teste umane e animali collocati nella parte superiore del muro meridionale della cattedrale di Traù. ${ }^{1}$ Con la costruzione del tetto sopra la terrazza della navata sud, i doccioni hanno perso la loro funzione originaria. ${ }^{2}$ Si sa da un documento d'archivio che scolpì i doccioni Petar Pozdančić: il 2 novembre dell'anno 1416 l'operario della cattedrale Nikola Petrov Mikacijev pagò allo scultore Petar Pozdančić da Sebenico 50 ducati e frumento per la realizzazione e la messa in opera dei doccioni. ${ }^{3}$ Uno dei doccioni dopo che si staccò dal muro negli anni settanta del XX secolo è oggi proprietà privata a Dubrovnik (Ragusa).

Tutte le teste sui doccioni presentano una morfologia coerente come opera dello stesso scultore: le arcate oculari delle teste umane hanno un taglio squadrato e le palpebre sono gonfie; in vicinanza degli occhi le palpebre sono evidenziate da grosse linee di contorno; alla radice del naso le arcate oculari terminano con linee che ricordano l'angolo di un triangolo sferico. La capigliatura è modellata a soffici riccioli, trecce, simili a grossi nastri. I riccioli - nastriformi, di taglio squadrato, sono di diametro triangolare. Accanto al collo delle figure si avvolgono rami con foglie, probabilmente per risolvere il passaggio tra le forme arrotondate delle teste e i prismi dei blocchi in pietra in cui gorgogliava

\footnotetext{
${ }^{1}$ IVEKOVIĆ. Ć. M., L'architettura e plastica della Dalmazia, Vienna 1910, Tab. 8.

${ }^{2}$ EITELBERGER V. EDELBERG, R., Die mittelalterlichen Kunstdenkmale Dalmatiens in Arbe, Zara, Traù, Spalato und Ragusa, beschrieben von Rudolg Eitelberger v. Edelberg, aufgenommen und dargestellt vom Architekten W. Zimmermann, Jahrbuch der Kaiserlich Königlichen Central-commission zur Erforschung und Erhaltung der Baudenkmale, Band V, Wien, str. 129-307.

${ }^{3}$ Riporta integralmente il documento PLOSNIĆ ŠKARIĆ, A., Prilog poznavanju građevinske povijesti trogirske katedrale u 15. stoljeću, Radovi Instituta za povijest umjetnosti 35, Zagreb 2011., str. 47, doc. n.3.
} 


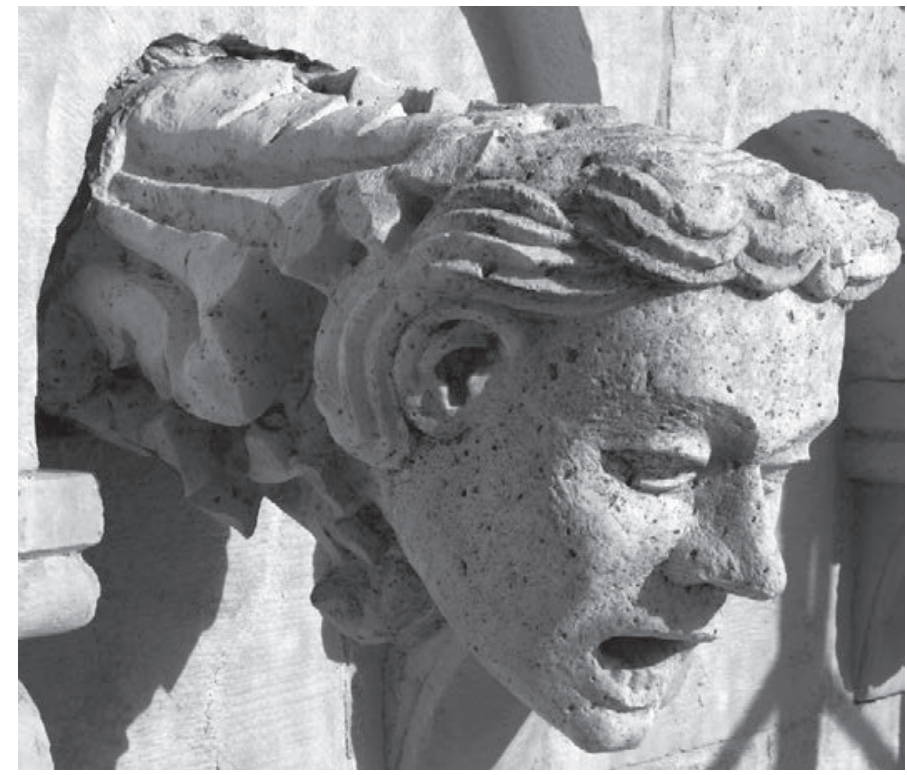

Fig. 1. Petar Pozdančić, doccione sotto la terrazza della navata sud (secondo doccione contando da sinistra a destra) l'acqua. La maggior parte dei rami ha foglie di forma molto appuntite; alcune sono di taglio squadrato, seghettato. I rami hanno al centro profondi intagli.

Il maestro Petar Pozdančić per un'attività così importante aveva verosimilmente i suoi aiutanti. Si sa che Ratko (Alegreto) Ivanov Miličević da Curzola nell'anno 1417 fu preso a bottega da Petar Pozdančić residente a Traù. ${ }^{4}$ A lui Petar Pozdančić lasciò i suoi attrezzi nel testamento dettato a Venezia il 28 aprile $1421 .{ }^{5}$ Ratcho Milichevich lapicida de Curzola nell'anno 1413 si imparentò a Traù sposandosi con Klara, nipote del nobile Andrija Cega, e già allora è menzionato nei documenti come abitante di Traù. ${ }^{6}$

\section{LA TESTA MASCHILE SULLA MENSOLA CHE SORREGGE LA SCALA ESTERNA NEL CORTILE DEL PALAZZO DEL COMUNE}

La testa è collocata in un punto in vista: sulla mensola sotto l'arco della scala sotto le quali si trova l'atrio d'ingresso al cortile. Somiglia molto alle teste umane sui doccioni della cattedrale. La sua dimensione è leggermente superiore a quella naturale. Non è presentata rigidamente en face: rispetto alla mensola è leggermente ruotata a destra. ${ }^{7}$ La superficie del cranio, dalla fronte accentuatamente convessa, è molto tesa. La bocca è semiaperta. La testa è calva, ma con baffi e barba rigogliosi a nastri intrecciati. Nelle profonde cavità oculari le palpebre sono un po' gonfie. Vicino agli occhi le palpebre, inferiori e superiori, hanno doppie linee di contorno. Da entrambi i lati del volto, fino al mento e sotto il mento, sul collo e sul blocco in pietra, sulla mensola da cui sporge la testa si avvolgono rami e rametti con foglie stilizzate e di forma molto appuntita, simili a quelle sui doccioni della catttedrale. La testa ha le caratteristiche di un ritratto; in senso fisiognomico la persona rappresentata appare energica, concentrata, assorta nei suoi pensieri. Una tale libertà nello scolpire sculture di dimensioni molto grandi se la poteva concedere uno scultore che aveva un ruolo importante nella costruzione/ restauro del palazzo, che era stato distrutto, com'è noto, nel giugno dell'anno 1420 durante il bombardamento della città da parte di Venezia. ${ }^{8} \mathrm{E}$ possibile che la testa originariamente anche prima del 1420 avesse un'altra collocazione, per esempio sulla facciata medioevale d'un tempo del Palazzo del Comune. Infatti, prima della ricostruzione ultimata nel 1890, il palazzo era un complesso di più edifici di altezze e date diverse. I progettisti del restauro di gusto romanticheggiante, troppo libero, dell'odierno Palazzo del Comune sono stati l'ing. Josip Slade e il prof. Ante Bezić, ma non ci sono pervenuti i documenti sullo stato dell'edificio prima del restauro. ${ }^{9} \mathrm{Al}$ tempo del restauro del palazzo

\footnotetext{
${ }^{4}$ FISKOVIĆ, C., Naši graditelji i kipari XV. i XVI. stoljeća u Dubrovniku, Zagreb 1947., str. 99.

${ }^{5}$ CONNELL, S., The Employment of Sculptors and Stonemasons in Venice in the Fifteen Century, New York, London 1988, p. 88; NOVAK KLEMENČIČ, R., Kiparski ukras Kneževa dvora u Dubrovniku u 15. stoljeću, Nekoliko priloga, Prilozi povijesti umjetnosti u Dalmaciji 39, Split 2005, p. 299.

${ }^{6}$ FISKOVIĆ, C., Iz Duknovićeva kruga u Trogiru i u Mađarskoj, Prilozi povijesti umjetnosti u Dalmaciji 23, Split 1983., 194-195, n. 22.

${ }^{7}$ La foto della testa è riportata in IVEKOVIĆ. Ć. M. , L'architettura e plastica della Dalmazia, Vienna 1910, Tab.7.

${ }^{8}$ LUCIĆ, I., Povijesna svjedočanstva o Trogiru, vol. II., Split, 1979., str. 956.
} 


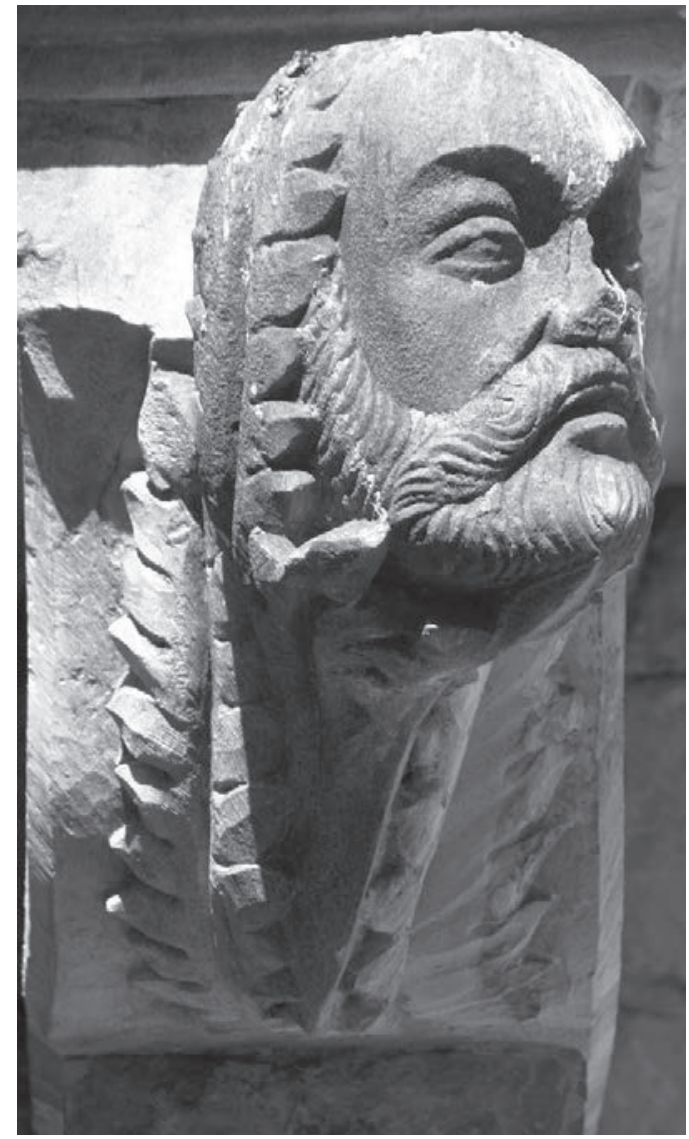

Fig. 2. Testa sulla mensola della scala esterna nel cortile del Palazzo del Comune a Traù (Foto: M. Mijić)

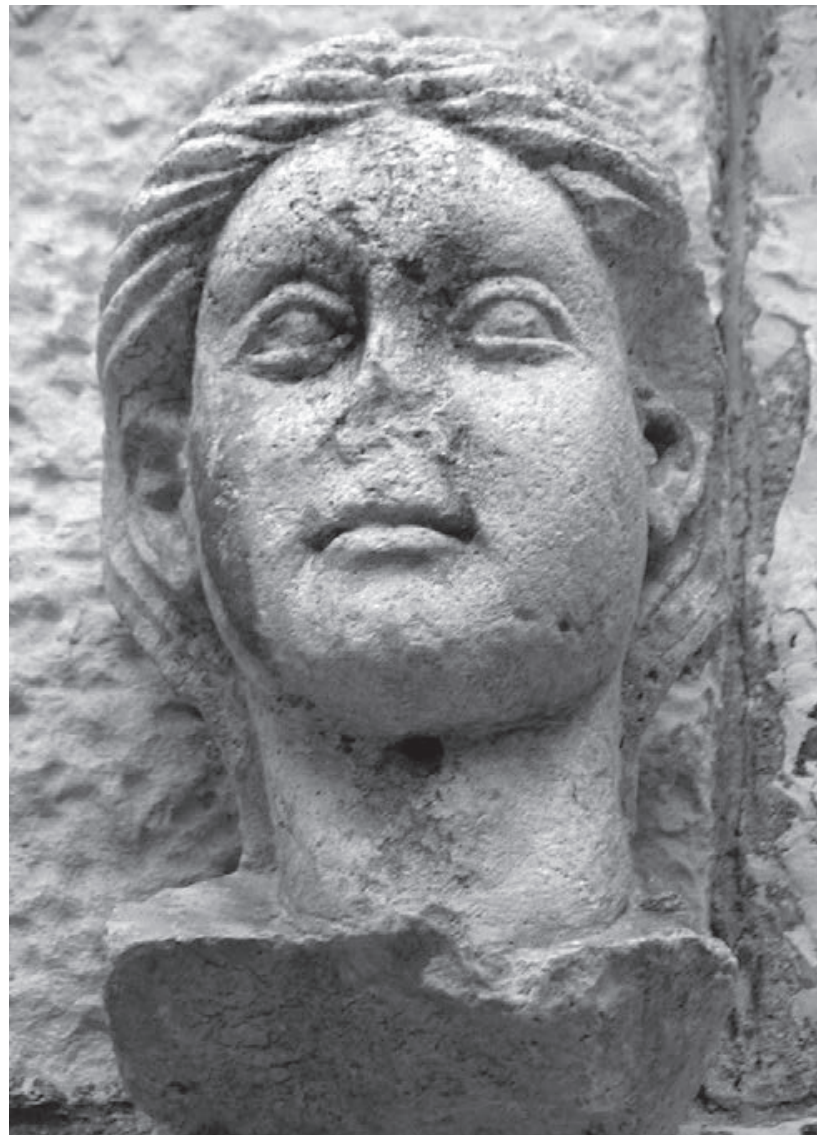

Fig. 3. Testa immurata sul muro sud del cortile del Palazzo del Comune a Traù (Foto: M. Mijić)

nei muri del cortile furono immurati molti frammenti del palazzo originario, ma anche provenienti da altre rovine, tra le quali il distrutto Palazzo vescovile. ${ }^{10}$

Questa testa secondo quanto tramanda la tradizione sarebbe, come si presume, l'autoritratto del maestro Matija Gojković, che negli anni venti del XV secolo lavorava al restauro del danneggiato campanile della cattedrale. ${ }^{11}$ Era stata avanzata l'ipotesi che Matija Gojković fosse l'architetto del Palazzo comunale e del complesso architettonico cui apparteneva, ${ }^{12}$ ma è stata respinta per mancanza di prove d'archivio. ${ }^{13}$ Propongo, quindi, una nuova attribuzione: la testa potrebbe rappresentare proprio Petar Pozdančić che era attivo come lapicida alla costruzione e alla decorazione di una parte del Palazzo del Comune, anche se non vi sono documenti d'archivio.

\section{LA TESTA FEMMINILE IMMURATA SUL MURO SUD DEL CORTILE DEL PALAZZO DEL COMUNE}

La testa ha dimensioni leggermente minori di quelle naturali. Dato che se ne sono conservati il collo e piccola parte delle spalle si può concludere che apparteneva a una scultura più grande (una

\footnotetext{
${ }^{9}$ FISKOVIĆ, C., Arhitekt Josip Slade, Trogir, 1987., str. 24-25; PIPLOVIĆ, S., Graditeljstvo Trogira u XIX. stoljécu, Split 1996., str. 55-62.

${ }^{10}$ RADIĆ, D., Zaštita spomenika u Trogiru tijekom XIX. stoljeća. Radovan, n. 3., Trogir 2005., str. 102-130.

${ }^{11}$ DELALLE, I., Trogir,. Vodič po njegovoj historiji, umjetnosti i životu, Split 1936., str. 54; FISKOVIĆ, I., Gotička kultura Trogira, Moguénosti 10-11, Split 1980., str. 1054.

${ }^{12}$ IVEKOVIĆ. Ć. M., Dalmatiens Architektur und Plastik (text), Wien 1910, str. 21.

${ }^{13}$ KARAMAN, LJ., Umjetnost u Dalmaciji XV. i XVI. vijeka, Zagreb 1933., 36.; PLOSNIĆ ŠKARIĆ, A., (3), 54.
} 


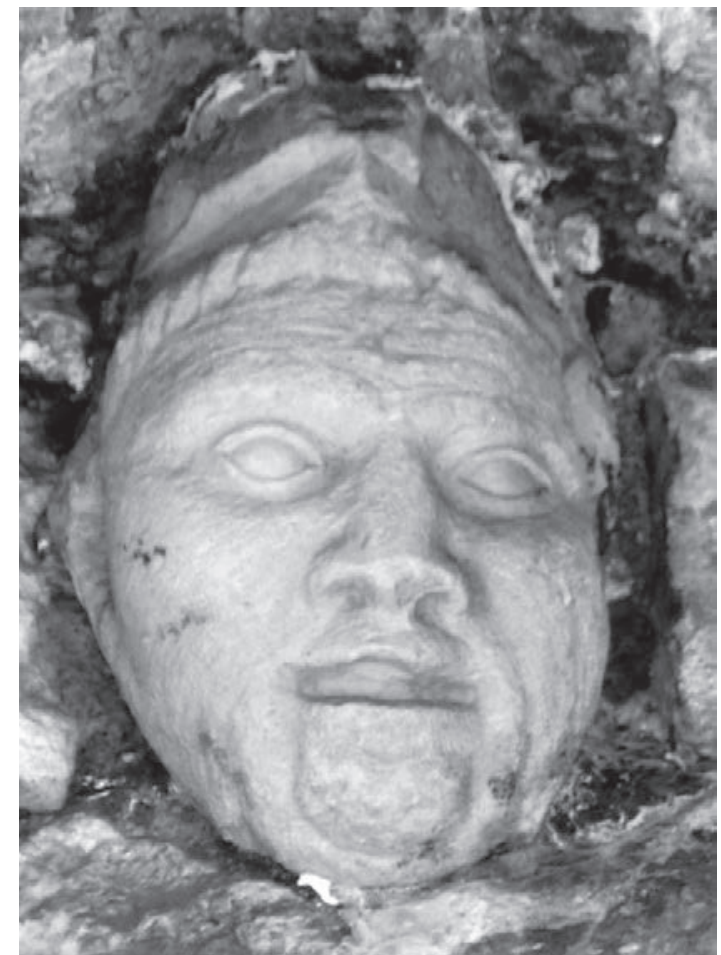

Fig. 4. Testa immurata sotto il grande arco della scala esterna nel cortile del Palazzo del Comune a Traù (Foto: M. Mijić)

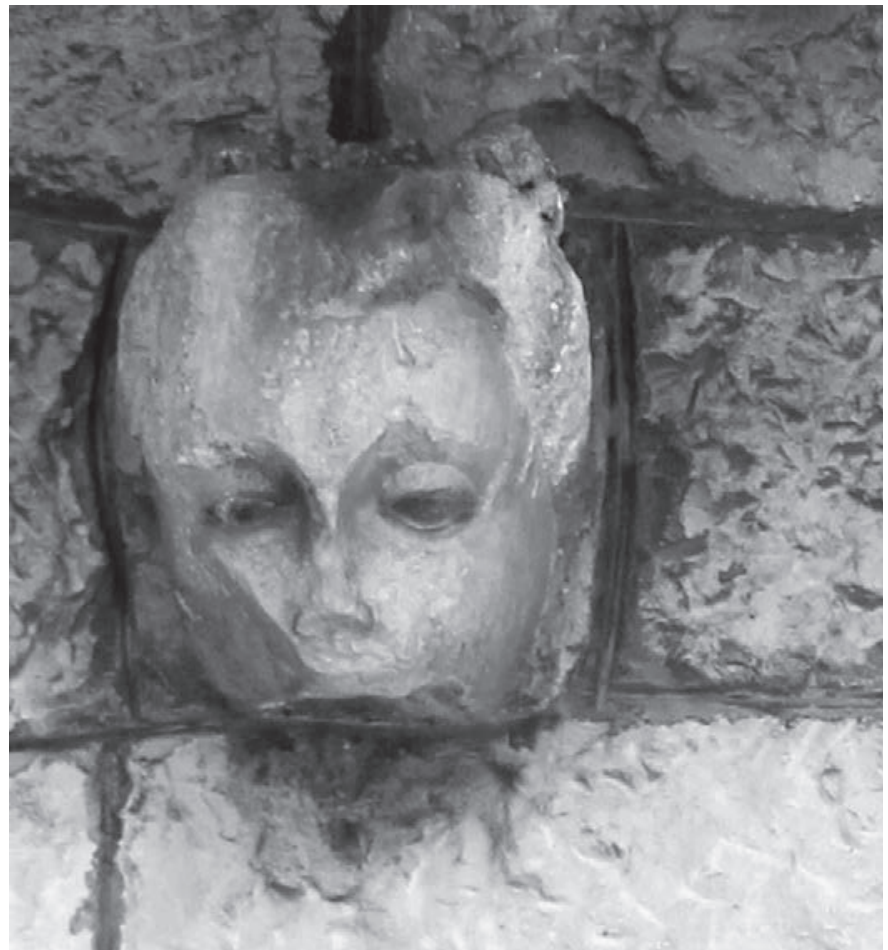

Fig. 5. Frammento di testa immurata sotto il tetto del muro ovest del Palazzo del Comune a Tra $\square$ (Foto: M. Mijić)

statua o almeno un busto). Si tratta evidentemente di uno spolia tardomedioevale. Anche questa testa femminile presenta ciocche di capelli stilizzate, ondulate come grossi nastri di taglio squadrato e di diametro triangolare, proprio come sui baffi e la barba della testa maschile sulla mensola sotto la scala, e come sulle figure sui doccioni. Un'altra caratteristica formale comune alle teste di Pozdančič sui doccioni è il taglio squadrato delle arcate oculari con le palpebre dai contorni marcati. Anche le bocche sono semiaperte. Si tratta di una scultura di una certa qualità, che riesce ad esprimere soddisfazione psichica con il sorriso vibrante. Si tratta forse della rappresentazione di un'allegoria dalle denotazioni positive, della visualizzazione di una virtù come si usava sugli edifici pubblici?

\section{LA TESTA MASCHILE SOTTO L'ARCO SUPERIORE DELLA SCALA ESTERNA DEL PALAZZO DEL COMUNE.}

La testa è di dimensioni naturali ed è immurata proprio sotto l'arco acuto della parte superiore della scala esterna, in un luogo poco illuminato e poco visibile. ${ }^{14}$ Originariamente aveva funzione portante: infatti, al centro della testa si notano i resti di un elemento architettonico profilato. Le narici sono molto larghe; la bocca aperta. La forma delle arcate oculari e delle sopracciglia rimanda alle teste sui doccioni. Il volto non è privo di espressione psichica cui contribuiscono le rughe. Si tratta evidentemente di uno spolia tardomedioevale. Si è già fatto notare che della testa potrebbe essere autore lo stesso scultore della testa sulla mensola che sorregge la scala esterna nel cortile del Palazzo Comunale. ${ }^{15}$

\section{IL FRAMMENTO DI TESTA DI DIMENSIONI NATURALI IMMURATO SUL MURO OVEST DEL CORTILE, IN ALTO SOTTO LA FALDA DEL TETTO}

Non mi risulta che questo frammento sia ricordato dalla letteratura critica. Rappresenta probabilmente una figura femminile. La testa è molto danneggiata, ma a causa della posizione è difficile

\footnotetext{
${ }^{14}$ Per quanto ci risulta riporta la fotografia della testa per la prima volta PLOSNIĆ ŠKARIĆ, A., (3), sl. 34.

${ }^{15}$ PLOSNIĆ ŠKARIĆ, A.,(3), str. 236.
} 


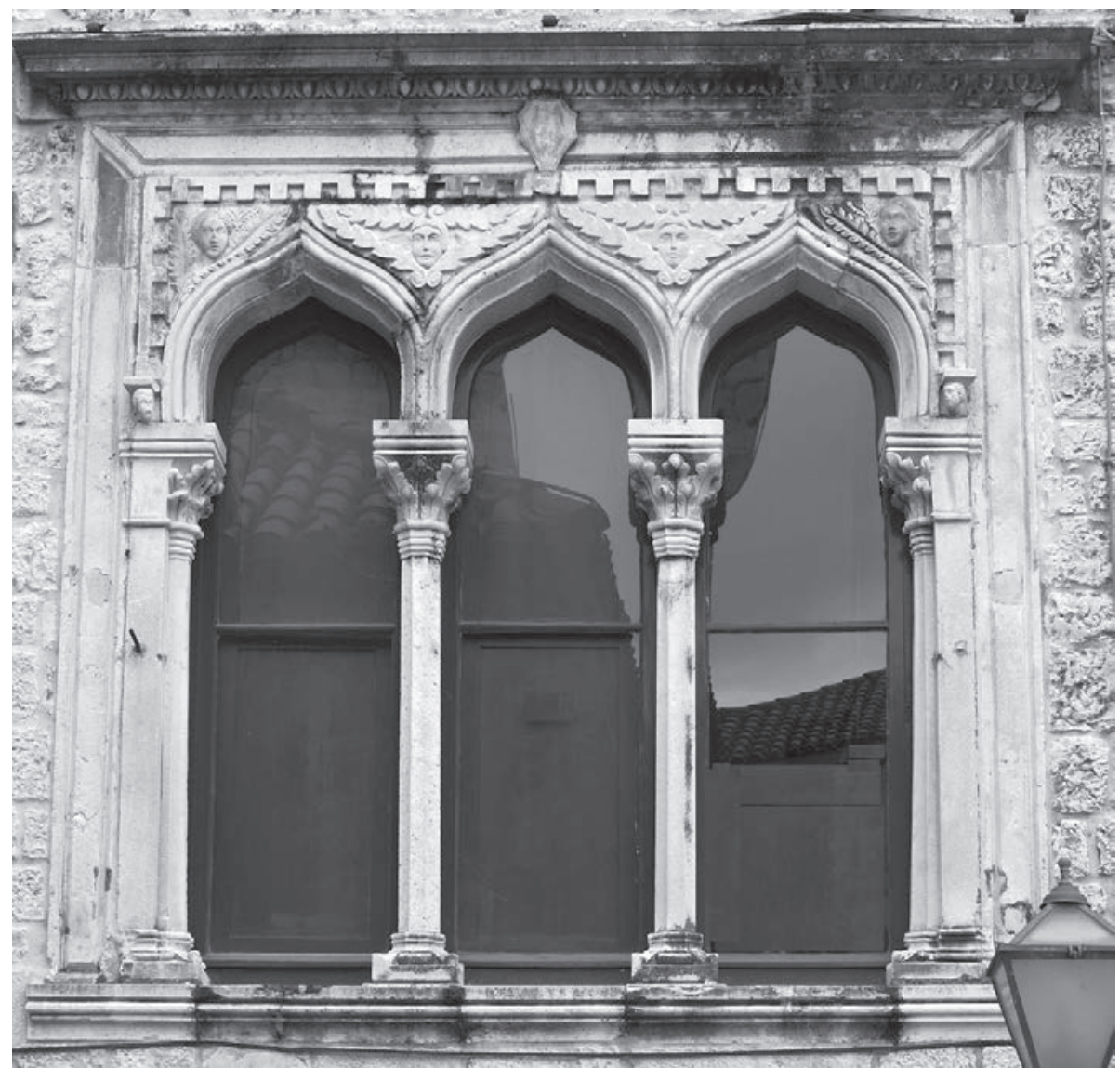

Fig. 6. Trifora sul Piccolo Palazzo Cippico a Traù (Foto: M. Mijić)

esaminarla. Anche in questo caso è chiaro che si tratta di uno spolia tardomedioevale. Si è conservata la parte superiore: la fronte e gli occhi, e i sovrastanti archi acuti. Anche questa testa potrebbe essere opera della bottega di Pozdančić.

\section{LA TRIFORA SUL PICCOLO PALAZZO CIPPICO}

A livello del primo piano, sulla facciata est del Piccolo Palazzo Cippico, sulla via principale, di fronte alla Loggia della Cattedrale spiccano due trifore una delle quali, quella di sinistra - a sud, è una ricostruzione in facsimile.

La trifora di destra, a nord, si è perfettamente conservata; la cornice rinascimentale risale a quando fu collocato lo stemma a forma di testa equina con gli emblemi araldici del casato dei Cippico. Questa parte del Palazzo era un tempo un'abitazione a se stante che apparteneva nella prima metà del XV secolo alla famiglia di mercanti Salamunić. ${ }^{16}$ Questa trifora presenta elementi decorativi simili a quelli che si ripetono sulle bifore del primo piano del campanile della cattedrale di Traù: per esempio i pilastrini di forma poligonale sotto i cui capitelli si sussegue una serie di strette fasce (anelli). Ma, i capitelli sulla trifora non sono simili a quelli sulla bifora del primo piano del

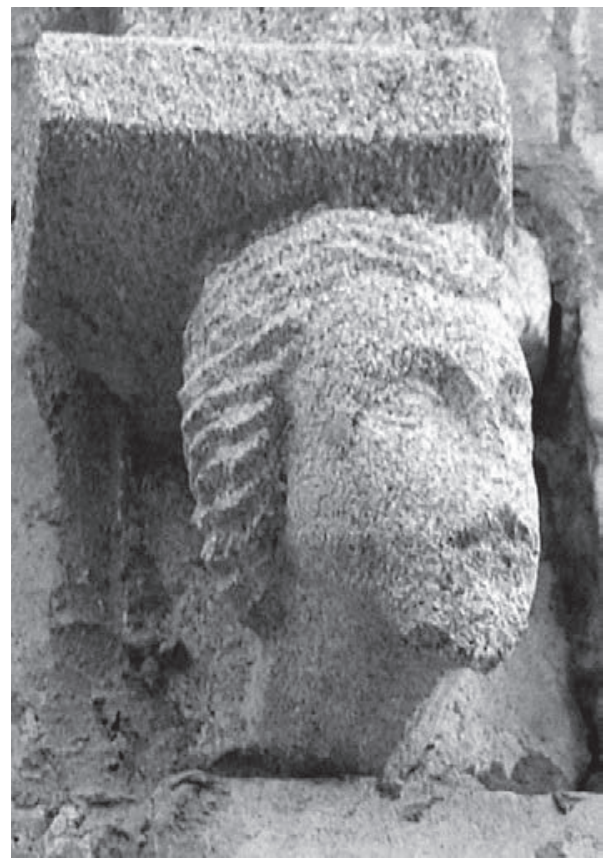

Fig. 7. Testa, dettaglio sul lato sinistro della trifora sul Piccolo Palazzo Cippico a Traù (Foto: M. Mijić)

${ }^{16}$ PLOSNIĆ ŠKARIĆ, A., (3), 83. 


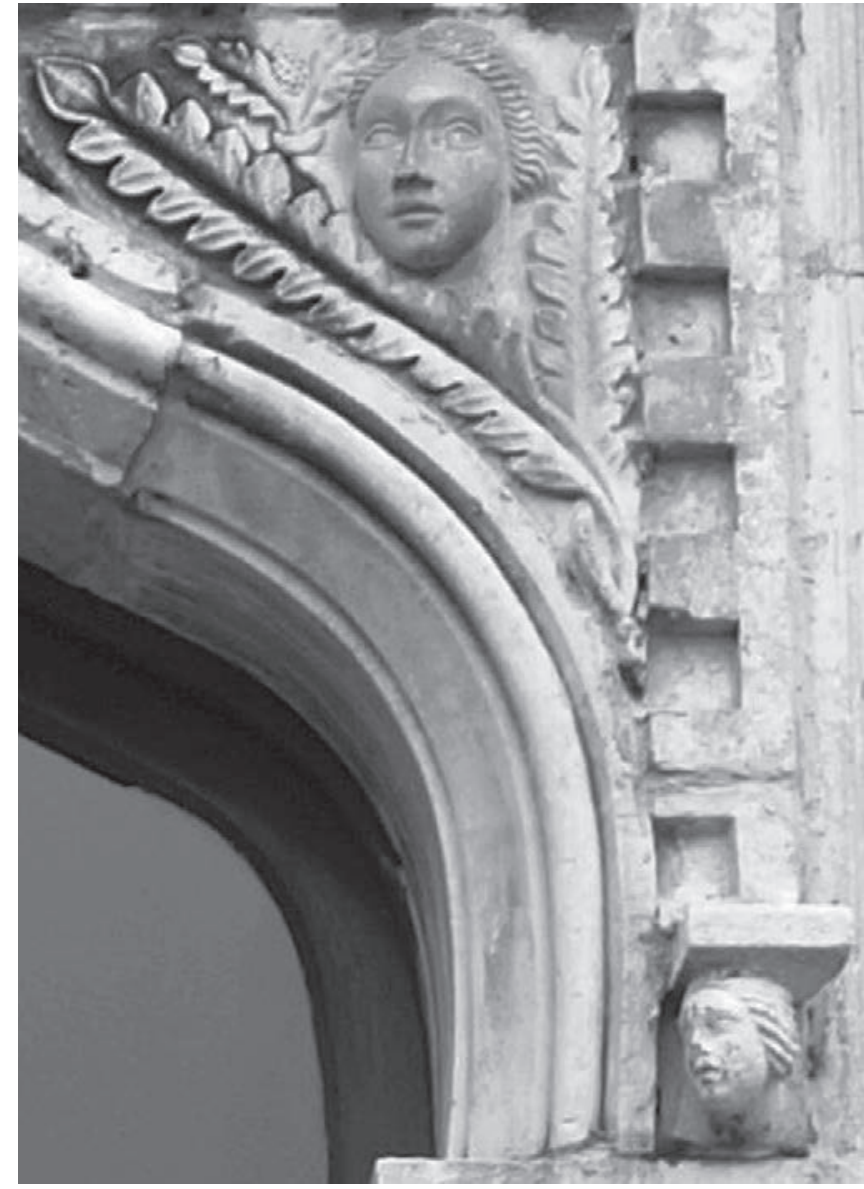

Fig. 8. Parte del lato destro della trifora sul Piccolo Palazzo Cippico (Foto: M. Mijić)

campanile, bensì del tutto identici ai capitelli sui semipilastri che sorreggono le arcate cieche gotiche dello stesso piano. Lungo le cornici della trifora si susseguono dentellature rettangolari identiche a quelle intorno alle arcate cieche in cima al primo piano del campanile.

La trifora è riccamente decorata. Su entrambi i lati della trifora, sotto i semicapitelli sui semipilastri, collocati accanto alla cornice, spiccano due piccole teste: sul lato sinistro una testa maschile (?) di forma allungata; sul lato destro una testa femminile (?) di modellato più morbido. Ciascuna di queste piccole teste è sormontata da abachi privi di qualsiasi funzione architettonica. Le teste non sono rappresentate frontalmente ma appena ruotate. Le loro chiome sono a riccioli nastriformi; i volti hanno le caratteristiche arcate oculari di taglio squadrato. Pur essendo piccole sono espressive, quella femminile (?) con la bocca semiaperta ha un'espressione di dolore; quella maschile (?) a sinistra fissa un punto lontano.

Tra gli archi della trifora sono rappresentati a rilievo volti giovanili (di angeli?) collocati tra rami con foglie seghettate. I rami accanto alle teste di angeli terminano a losanga. Anche su questi rilievi con teste giovanili s'intrecciano riccioli nastriformi. Gli occhi sono infossati, con arcate di taglio squadrato. Le palpebre inferiori e superiori sono rimarcate. I volti sono ovali, ma le chiome pettinate in modo che la fronte termina come un arco ogivale, proprio come sul viso della testa femminile immurata nel cortile del Palazzo del Comune. I volti ( di angelie) tra gli archi delle trifore hanno un'espressione placida. Come è già stato osservato sono sculture di grande qualità. ${ }^{17} \mathrm{La}$ fattura delle teste e il motivo a foglie seghettate suggeriscono l'attribuzione della trifora a Petar Pozdančić. Gli altri due rilievi in pietra al centro della trifora, con teste tra foglie sono copie-restauri della metà del XX secolo.

\section{LO STEMMA E IL FRAMMENTO DI FINESTRA IMMURATI SULLA TERRAZZA DI PALAZZO LUCIĆ}

Sul muro sud sopra la terrazza in Palazzo Lucić è immurato lo stemma con gli emblemi araldici del casato dei Lucić (Lucio,Lucius). Lungo lo scudo araldico s'avvolgono rami a foglie appuntite i quali terminano a losanga come quelli raffigurati sulla trifora sul Palazzo Piccolo Cippico. Sopra lo scudo è rappresentato un angelo a mezzo busto la cui testa, specie la fattura della chioma somiglia a quella descritta della testa femminile del cortile del Palazzo del Comune: somiglia anche alle piccole teste sulla trifora sulla facciata del Palazzo Piccolo Cippico.

Nel frammento di finestra gotica immurato sopra lo stemma Lucić, si trova una testa dal viso barbuto, lavoro di qualità e di dimensioni naturali, tra rametti terminanti a losanga. Si deve ricordare

\footnotetext{
${ }^{17}$ PLOSNIĆ ŠKARIĆ, A., (3), str. 236.

${ }^{18}$ FISKOVIĆ, C. "Lučićeva rodna kuća“, Zbornik Historijskog instituta Jugoslavenske akademija posvećen I. Luciusu-Lučiću povodom 200-godišnjice djela „De Regno Dalmatiae et Croatiae“, Zagreb 1969., str. 45-60, sl. 6. i 7.
} 


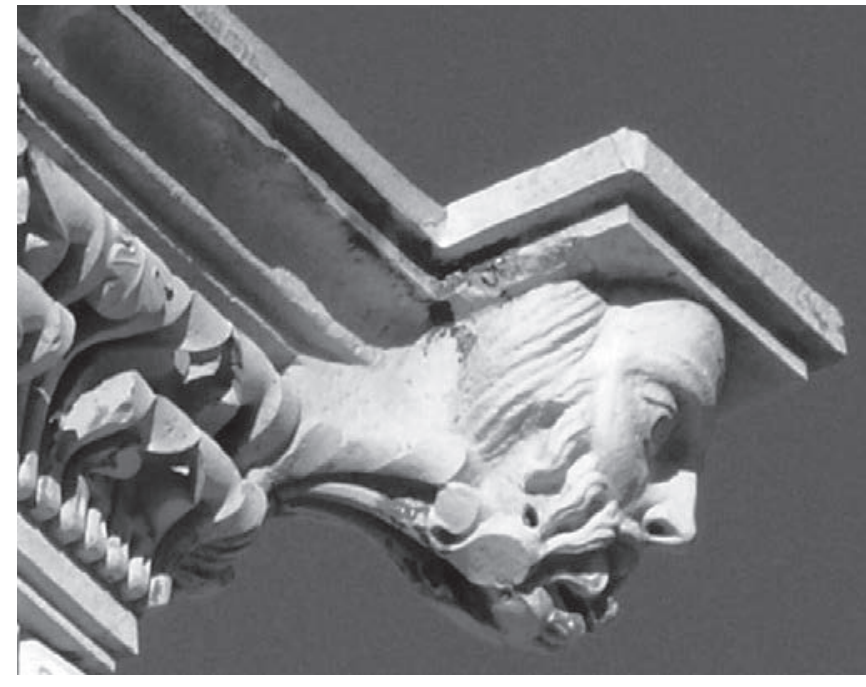

Fig. 10. Testa sullo spigolo nord-est del campanile della cattedrale di Tra $\square$, lungo il cornicione tra il primo e il secondo piano (Foto: M. Mijić)

che anche questo volto espressivo non è rappresentato proprio frontalmente.

Lo stemma e il frammento di finestra gotica del Palazzo Lucić sono attribuiti allo scultore veneziano Nicola Dente detto Cervo. ${ }^{18}$ Tuttavia, sono più vicini allo stile di Petar Pozdanačić. Nicola Dente, infatti, modella le teste in modo meno plastico, en face.

\section{PETAR POZDANČIĆ E IL PRIMO PIANO DEL CAMPANILE DELLA CATTEDRALE DI TRAÙ}

Risale all'anno 1264 il primo documento rilasciato nei pressi del campanile della cattedrale (...iuxta campanile sancti Lurentii). ${ }^{19}$ Non sappiamo che aspetto avesse il campanile. Forse era una costruzione bassa, temporanea, a vela. Un artista veneziano, Zanino (magister Zaninus, Çanninus..) figlio del defunto Salchi, aveva firmato il 14 maggio 1347 il contratto di protomaestro alla costruzione della cattedrale e del campanile. ${ }^{20}$ Con lui a Traù si ricordano i suoi due figli, sempre costruttori: Salchietus e Jacomellus. ${ }^{21}$ Già prima, nel 1344, maestro Zanino conferma a nome suo e dei suoi figli di aver ricevuto 33 ducati dall'operario per l'affitto e per un terzo della prima paga di 100 ducati. ${ }^{22}$ Il campanile subì ingenti danni durante i bombardamenti veneziani nel giugno dell'anno 1420. Con il contratto del 18 aprile dell'anno 1421 maestro Matija Gojković si assume l'impegno di

\footnotetext{
${ }^{19}$ BARADA, M., Trogirski spomenici, dio 1., Zapisci pisarne općine Trogirske, sv. I., od 21. X. 1263. do 22. V. 1273., Monumenta spectantia historiam slavorum meridionalim, knjiga 44, Zagreb 1948., str. 48.

${ }^{20}$ KARAMAN, LJ., Portal majstora Radovana u Trogiru, Rad JAZU, knjiga 262, Zagreb 1938., str. 72.

${ }^{21}$ PLOSNIĆ ŠKARIĆ, A., (3), 221-222.

${ }^{22}$ Codex diplomaticus Regni Croatiae, Dalmatiae et Slavoniae, vol. XI, (1913.), str. 139.
} 
riparare il campanile con l'operario Dragolin Nikolin, ma anche altri danni alla cattedrale e questo entro due soli anni. ${ }^{23}$ A maestro Gojković si ordina di riparare il cornicione del campanile in modo solido com'era prima di essere danneggiato. ${ }^{24} \mathrm{Al}$ primo piano del campanile, al suo interno si sono firmati i maestri Matej (Gojković) e Stjepan, come si legge dalla lapide in data 27 aprile $1422 .{ }^{25} \mathrm{Si}$ tratta, a parere unanime, dell'iscrizione che riguarda la ricostruzione del campanile.

Il primo piano del campanile impressiona per la pienezza architettonica della sua massa; solo nella parte inferiore è aperto con due paia di bifore gotiche. Tra le bifore s'alza un pilastro affiancato da alti e stretti semipilastri angolari che reggono insieme alle mensole i quattro archi ogivali delle arcate cieche gotiche. Pilastri affiancati da semipilastri s'alzano anche a lato delle bifore.

Sopra le arcate cieche corre il cornicione terminale che separa il primo piano dal secondo. Il primo piano del campanile non è identico su tutti i suoi lati. Le doppie bifore si trovano, infatti, solo sul lato ovest e sud (sulla piazza).

Al primo piano si trova un gran numero di elementi ornamentali: teste umane e animali su mensole che reggono arcate cieche, e una testa tra foglie su ogni lato del cornicione terminale. Tutte, specie quelle sul muro ovest, meritano analisi dettagliate.

Tra le teste al primo piano spicca maggiormente quella che aggetta nello spazio sullo spigolo nordest del campanile. Si tratta dell'unica testa eseguita a tutto tondo. Il suo collo aggetta dal cornicione terminale che separa il primo dal secondo piano. Su questa testa è posato un abaco doppio. Lo stesso motivo, come già ricordato, appare anche su due piccole teste umane sulla trifora del Palazzo Piccolo Cippico. Questa testa si trova in un punto inaccessibile ed è un problema fotografarla en face senza impalcature. Per questo motivo ne abbiamo solo una fotografia di profilo che non permette una descrizione e un'analisi più dettagliate. Rappresenta un uomo barbuto. La barba è a ciocche intrecciate. La fronte è molto prominente come quella della testa sopra la mensola sotto la scala del Palazzo del Comune. Le narici sono larghe. Le arcate sopraccigliari sono rimarcate e gli occhi hanno pupille a profondi cerchi. Allo stesso modo che sui doccioni e sulle altre sculture descritte anche su questa testa sullo spigolo del campanile le ciocche dei capelli e della barba sono nastriformi con diametro triangolare. Già dalla barba, lungo il mento e il collo si susseguono le foglie. Il ramo con foglie sotto il collo ha al centro profondi intagli come quelli delle teste sui doccioni. Le foglie, alcune arrotondate altre appuntite, sono identiche a quelle sul cornicione terminale del primo piano del campanile e, come si è già detto, sui capitelli e i semicapitelli della trifora sul Piccolo Palazzo Cippico.

L'espressione psichica della testa, leggermente ruotata, rivolta in basso, denota severità e concentrazione. Attribuisco anche questa testa a Petar Pozdančić al quale si dovrebbero attribuire la parte superiore, terminale del primo piano del campanile: il cornicione e le teste sotto le mensole.

Il Sebenicense Petar Pozdančić fu Radmillo (magister Petrus lapicida quondam Radmilli de Sebenico) giunse a Traù come maestro lapicida già affermato: 1'1 dicembre del 1405 firmò il contratto per scolpire numerose sculture per la cappella di San Simeone nella chiesa di Santa Maria Maggiore a Zara, anche se non si sa se portò a termine il suo impegno. ${ }^{26} \mathrm{~A}$ Bribir, nel 1415, costruì la volta della chiesa francescana. ${ }^{27}$ Si tramanda che fosse attivo anche a Venezia dove probabilmente realizzò grandi imprese avendo un suo aiuto, il già menzionato Ratko (Alegreto) da Curzola, figlio di Ivan Miličević con cui aveva già collaborato a Traù. ${ }^{28}$ Questo stesso Ratko, figlio di Ivan Miličević, è menzionato in

${ }^{23}$ LUCIĆ, I., (8), str., 957-959; FARLATI, D., Trogirski biskupi, Split 2010., str. 311-313; PLOSNIĆ ŠKARIĆ, A., (3), str. 148 , doc. 4.

${ }^{24}$ LUCIĆ, I., (8), str. 958.

${ }^{25}$ JACKSON, T. G., Dalmatia, The Ouarnero and Istria, vol. II, Oxford, 1887, str. 138-139.

${ }^{26}$ FISKOVIĆ, C. Zadarski sredovječni majstori, Split 1959., str. 46-47, 156.; HILJE, E., Glava arkanđela Gabrijela iz crkve Sv. Ivana u Zadru, Radovi Instituta za povijest umjetnosti 21 (1997), str. 26.

${ }^{27}$ FISKOVIĆ, C., (26), 46.

${ }^{28}$ FISKOVIĆ, C. Hrvatski umjetnici u Mlecima, Mogućnosti III/br. 1, Split 1956., str. 4; CONNELL, S. (5) 88; ČORALIĆ, L., U gradu svetoga Marka, povijest hrvatske zajednice u Mlecima, Zagreb 2001., str. 307. 
patria come Ratko Ivančić, grande imprenditore, attivo alla costruzione e ornamentazione di molte opere architettoniche a Ragusa, per esempio al palazzo del voivoda Sandalj Hranić, ${ }^{29}$ tra l'altro nel 1439 scolpì anche le bifore del Palazzo del Rettore. ${ }^{30}$

La città di Traù è ricca di architetture e opere d'arte in stile gotico, dai dipinti alle suppelletili liturgiche. ${ }^{31}$ I contributi di Petar Pozdančić e del suo collaboratore Ratko Milićević/Ivančić alla scultura traurina del tempo devono essere stati significativi.

Traduzione a cura di Nicoletta Rusotti Babić

\section{PRILOZI ZA PETRA POZDANČIĆA I NJEGOVU RADIONICU}

Petru Pozdančiću, sinu Radmilovom i njegovoj radionici atribuira se nekoliko radova u Trogiru: četiri glave uzidane u dvorištu Komunalne palače, triforu na tzv. Maloj palači Cippico te grb i ulomak gotičkog prozora iz palače Lucić. Iznosimo i pretpostavku da je majstor (lapicida) Pozdančić doprinjeo ukrašavanju završnog dijela prvog kata zvonika Trogirske katedrale.

Kao polazište za ove atribucije su vodorige (gargouilles) s ljudskim i životinjskim glavama postavljene visoko na južnom zidu. Za te kamene vodorige poznato je prema arhivskoj ispravi da ih je izradio klesar Petar Pozdančić. Za taj posao bio je isplaćen 2. studenog 1416.

Sve ljudske glave na vodorigama imaju dosljednu morfologiju kao rad istog klesara: očni lukovi figura su oštro rezani s natečenim kapcima; uz same oči, kapci su naznačeni zadebljanjima obrubljenim linijama; nad korijenom nosa očni lukovi završavaju linijama koje podsjećaju na kut sfernog trokuta. Vlasi su oblikovane tako da se isprepliću poput tankih uvojaka, pletenica, sličnima debljim vrpcama. Ti uvojci slični vrpcama imaju u presjeku oblik trokuta. Uz vrat figura povijaju se lisnate grane, valjda zato da bi se postigao prijelaz između zaobljenja glavâ i prizmâ kamenih blokova u kojima je kanal u kojem je grgutala voda. Većina grana ima veoma šiljaste listove; poneki su tako oštri da podsjećaju na zupce pile. Grane pak po sredini imaju duboka užljebljenja.

Majstor Petar Pozdančić vjerojatno je za tako zamašan posao morao imati pomagače. Poznato je da je Korčulanin Ratko Ivanov Miličević 1417. godine bio primljen u radionicu Petra Pozdančića nastanjenog u Trogiru.

Muška glava na konzoli koja pridržava vanjske stepenice u dvorištu Komunalne palače veoma je slična ljudskim glavama na vodorigama na katedrali. Oplošje volumena lubanje, posebno izrazito konveksnog čela, veoma je napeto. Usta su poluotvorena. Glava je ćelava no s bujnim brkovima i bradom poput isprepletenih vrpca. U dubokim očnim šupljima kapci su malo natečeni. Uz oči gornji i donji kapak naznačeni su sa po dvije linije. Usta su napola otvorena. Uz obje strane lica, do brade i ispod brade, na vratu i na kamenom bloku, na konzoli iz koje strši glava, savijaju se grane i grančice s izrazito šiljastim, stiliziranim lišćem na način istovjetan kao i na vodorigama na katedrali. Glava ima portretna obilježja; u fiziognomijskom smislu prikazana osoba djeluje energično, zagledana je i zaokupljena svom promislima.

Prema tradiciji glava je, navodno, autoportret majstora Matije Gojkovića koji je dvadesetih godina XV. stoljeća bio zaposlen na obnovi oštećenog zvonika katedrale. Iznesena je čak pretpostavka da je Matija Gojković bio graditelj Komunalne palače. No, nije li možda prikazan upravo Petar Pozdančić?

\footnotetext{
${ }^{29}$ GRUJIĆ, N. Kuća u gradu, Zagreb 2013., str. 115, 120, 141.

${ }^{30}$ FISKOVIĆ,C. (28), op.cit. 4; GRUJIĆ, N.( 2008), „Onofrio di Giordano della Cava i Knežev dvor u Dubrovniku“, Zbornik Dana Cvita Fiskovića - II. Renesansa i renesanse u umjetnosti Hrvatske, Zagreb 2008., str. 34.

${ }^{31}$ FISKOVIĆ, I., (31), str. 1036-1065.
} 
Projektanti romantičarske, suviše slobodne restauracije postojeće Komunalne palače bili su ing. Josip Slade i prof. Ante Bezić koji nisu ostavili za sobom dokumentaciju zatečenog zdanja. U doba restauracije palače u zidove oko dvorišta ugrađeni su mnogi ulomci iz prvobitne palače, ali i oni preneseni s drugih ruševnih zdanja, među ostalim i iz porušene Biskupove palače.

Ženska glava- nešto manja od prirodnih dimenzija, ugrađena je na južnom zidu dvorišta Komunalne palače. Očito radi se o kasnosrednjovjekovnoj spoliji. S obzirom na činjenicu da je sačuvan vrat i mali dio ramena, može se zaključiti da je bila dio veće cjeline (tijela ili barem poprsja). I na ovoj ženskoj glavi, na njenoj kosi, prepliću se stilizirani pramenovi vlasi, uvojci kose poput debljih vrpca oštro rezanih, trokutastog presjeka, jednako kao i na brkovima i bradi muške glave na konzoli pod stubištem, te isto kao i na figurama na vodrigama. S Pozdnačićevim glavama, s onima na vodorigama, povezuju je također i druga formalna obilježja; oblikovanje oštrih očnih lukova i naglašeni rubovi kapaka. Radi se o prilično kvalitetnoj skulpturi, na kojoj je postignuta psihička ekspresija zadovoljstva, gotovo titravog osmjeha. Moguće je da se radilo o prikazu neke alegorije, pozitivnih denotacija, o vizualizaciji neke vrline?

Muška glava ispod gornjeg luka vanjskog stubišta Komunalne palače. Glava, očito kasnosrednjovjekovna spolija, naknadno je ugrađena, visoko ispod samog šiljastog luka gornjeg dijela vanjskog stubišta, na sjenovitom i skrovitom mjestu. Izvorno je bila svojevrsni nosač; naime, na njenom tjemenu zapažaju se ostaci profiliranog arhitektonskog elementa.

Ulomak glave ugrađen na zapadnom zidu dvorišta Komunalne palače, visoko pod strehom. Glava je veoma oštećena, a s obzirom na svoj položaj teško je saglediva. Očito je da se i u ovom slučaju radi o kasnosrednjovjekovnoj spoliji. Vjerojatno se radi o prikazu ženske osobe. Sačuvani gornji dio lica i oči, posebno oštri očni lukovi, upućuju na mogućnost da je i ova glava rad Pozdančićeve radionice.

Trifora na Maloj Cipppicovoj palači. Na razini prvog kata, na istočnom pročelju Male palače Cippico, nad glavnom poprečnom ulicom, sučelice loži, dižu se dvije gotičke trifore od kojih je ona lijevajužna faksimilska rekonstrukcija.

Desna, sjeverna trifora u potpunosti je sačuvana. Naknadno je dobila renesansi okvir kad je postavljen grb u obliku konjske glave s heraldičkim obilježjima roda Cippico. Ova trifora ima dekorativne elemente slične onima koji se ponavljaju na biforama prvog kata zvonika. Na obje strane trifore, ispod polukapitela polustupova postavljenih uz okvir, istaknute su dvije sićušne glave: na lijevoj strani muška (?) glava izduženijeg oblika; na desnoj strani ženska(?)glava mekšeg obličja. Na tim malim glavama položene su po jedna ploča (abak) koje nemaju nikakvu arhitektonsku funkciju. Glave nisu prikazane frontalno već su lagano rotirane. Kosa je isprepletena u uvojke poput vrpca; na licima su im karakteristični, oštro rezani očni lukovi. Između lukova trifore nalaze se reljefno prikazana mladenačka lica (anđeli?) smještena između grana s listovima koji djeluju poput zubaca pile. I na tim glavama izvijaju se stilizirani uvojci slični vrpcama. Oči su postavljene u dubokoj šupljini, s oštrim lukovima. Lica su ovalnog oblika, no kosa je počešljana tako do čela ima pri vrhu oblik šiljastog luka, slično kao i na licu ženske glave ugrađene u dvorištu Komunalne palače.. Način oblikovanja glava i motiv listova poput zubaca pile navode na pretpostavku da je trifora djelo Petra Pozdančića i njegovog pomoćnika.

$\mathrm{Na}$ južnom zidu ponad terase u palači Lucić ugrađen je grb s heraldičkim obilježjima roda Lucić. Uz heraldički štit povijaju se grane oštrih listova koje pri dnu oblikuju petlju jednako kao i grane prikazane na trifori na Maloj palači Cippico. Nad štitom prikazano je poprsje anđela čija je glava, posebno način oblikovanja kose, slična opisanoj ženskoj glavi iz dvorišta Komunalne palače: slična je i malim glavama na trifori na pročelju Male Cippicove palače.

\section{ULOMCI NA TERASI PALAČE LUCIĆ}

U ulomak gotičkog prozora uzidan ponad grba Lucić, s kvalitetnim prikazom lica bradate glave gotovo prirodne veličine, među grančicama koje pri dnu oblikuju petlju. Valja napomenuti da ni ovo izražajno lice nije sasvim frontalno prikazano. Grb ima također obilježja svojstvena kiparstvu Petra Pozdančića. 


\section{PETAR POZDANČIĆ I PRVI KAT ZVONIKA TROGIRSKE KATEDRALE.}

Među glavama na prvom katu zvonika najistaknutija je ona koja strši u prostoru na sjeveroistočnom bridu zvonika. Jedina je izvedena u punoj plastici. Njen vrat izlazi iz završnog vijenca koji razdvaja prvi od drugog kata, a na glavi je položena dvodijelna ploča (abak). Smještena je na nepristupačnom mjestu, pa nam je dostupan tek njen snimak iz profila. Radi se o glavi bradatog muškarca. Brada je razdijeljena u izvijene uvojke. Celo je veoma ispupčeno isto kao i na glavi na konzoli pod stepeništem Komunalne palače. Naglašeni su i oštri lukovi nad očima na kojima su naznačene zjenice s udubljenjima kružnog oblika. Na isti način kao i na vodrigama i na ostalim opisanim skulpturama, tako i na ovoj glavi na bridu zvonika, pramenovi kose i brade oblikovani su poput vrpci trokutastog presjeka. Već od brade, niz podbradak i uz vrat nižu se listovi. Grana s listovima pod vratom ima u sredini duboko užljebljenje kao i glave na vodorigama. Ovu glavu također pripisujemo majstoru Petru Pozdančiću kojem bi trebalo pripisati gornji, završni dio prvog kata zvonika: vijenac i glave pod konzolama.

Šibenčanin Petar Pozdančić (magister Petrus lapicida quondam Radmilli de Sebenico) došao je u Trogir kao već afirmirani kamenar. 1. prosinca 1405. godine obvezao se isklesati brojne kipove za kapelu Sv. Šimuna u crkvi Sv. Marije u Zadru, premda nije poznato je li potpunosti ispunio svoje obaveze. Na Bribiru je 1415. godine presvodio franjevačku crkvu. Navodi se da je ovaj majstor djelovao i u Veneciji gdje je valjda izvodio pozamašne radove kad je tamo imao pomoćnika, već spomenutog Korčulanina Ratka (Alegreto), sina Ivana Miličevića s kojim je već surađivao u Trogiru.

Ključne riječi: Petar Pozdančić, gotička skulptura, Trogir 